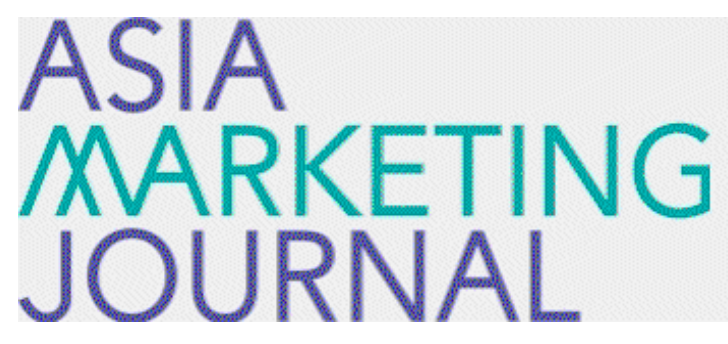

ASIA MARKETING JOURNAL

Volume 21 | Issue 1

Article 1

4-30-2019

\title{
The Effect of Rating Dispersion on Purchase of Experience Goods based on the Korean Movie Box Office Data
}

Lian Chen

Kang Jun Choi

Jae Young Lee

Follow this and additional works at: https://amj.kma.re.kr/journal

Part of the Marketing Commons

\section{Recommended Citation}

Chen, Lian; Choi, Kang Jun; and Lee, Jae Young (2019) "The Effect of Rating Dispersion on Purchase of Experience Goods based on the Korean Movie Box Office Data," Asia Marketing Journal: Vol. 21 : Iss. 1 , Article 1.

Available at: https://doi.org/10.15830/amj.2019.21.1.1

This Article is brought to you for free and open access by Asia Marketing Journal. It has been accepted for inclusion in Asia Marketing Journal by an authorized editor of Asia Marketing Journal. 


\section{The Effect of Rating Dispersion on Purchase of Experience Goods based on the Korean Movie Box Office Data}

Lian Chen*

Kang Jun Choi** Jae Young Lee***

Online platforms often provide rating information to customers to relieve the uncertainty they encounter when purchasing experience goods. Prior research has focused mostly on the roles of rating volume and the valence of an average rating among the various possibilities. However, less frequently investigated is the effect of rating dispersion, which may be associated with uncertainty regarding how well a product fits a customer's personal preference, on new trials of experience goods. In this study, we examine the effect of rating dispersion on new trials of experience goods and identify the conditions which intensify or reduce the effect. Empirical analyses of movie box office sales data and online rating data reveal three interesting findings. First, movie sales decrease as movie ratings become increasingly dispersed. Second, the negative effect of rating dispersion on movie sales is more pronounced with more rating volume. Third, this negative effect weakens when additional information about a movie is available (i.e., higher average rating, greater star power, and time since its release). We discuss the academic and practical implications of our findings.

Key words: rating dispersion, experience goods, fit uncertainty, rating information

\section{Introduction}

Experience goods are those for which product quality is mostly discoverable through direct experience of the product (Huang, Lurie, and Mitra 2009; Nelson 1970, 1974). Thus, it is hard for consumers to evaluate the quality of experience goods prior to purchase (Hong and Pavlou 2014; Nelson 1970; Weathers, Sharma,

\footnotetext{
* Graduate Student, Yonsei University

** Doctoral Candidate, Yonsei University

*** Assistant Professor, Yonsei University（jaelee@yonsei.ac.kr), Corresponding Author
} 
and Wood 2007; Zeithaml 1981), and ex-post evaluation varies across customers (Huang et al. 2009; Wan, Nakayama, and Sutcliffe 2012; Wright and Lynch 1995). When purchasing an experience good, therefore, consumers often refer to feedback from other consumers to resolve uncertainty and make more informed purchase decisions (Forsythe and Shi 2003; HarrisonWalker 2001: Pavlou and Gefen 2004).

To facilitate the purchase process, online shopping platforms often ask individual customers to rate a product, providing aggregated summaries of those ratings (Qiu, Pang, and Lim 2012; Zhu and Zhang 2010). For instance, Yelp (yelp.com) and Amazon (amazon.com) exhibit average ratings, the total number of reviews, and the overall star rating distribution, which enables consumers to see the dispersion of the ratings. Past studies have reported that information on customer ratings significantly drives sales, but the evidence is based mostly on the effect of the average rating (Chevalier and Mayzlin 2006: Chintagunta, Gopinath, and Venkataraman 2010; Dellarocas, Zhang, and Awad 2007) and rating volume (Duan, Gu, and Whinston 2008a; Duan, Gu, and Whinston 2008b; Liu 2006).

Only a few researchers have studied the effect of rating dispersion, but their results were not consistent; there is evidence of positive (Clemons, Gao, and Hitt 2006: Sun 2012), negative (Zhu and Zhang 2010), and non-significant associations with sales (Chintagunta et al. 2010; Moe and Trusov 2011). These findings may be conflicting for several reasons. First, the effect of rating dispersion on trial purchase was not a focal interest in past studies, which overlooked the varying effect of this factor across different products. Ignoring these differences not only limits the practical applicability of the findings, but may also skew the results. Second, the contexts of previous research were inconsistent; for instance, some investigated the effect based on a trial purchase (Chintagunta et al. 2010; Sun 2012; Zhu and Zhang 2010), while others studied it based on repeat purchase products (Clemons et al. 2006; Moe and Trusov 2011). Third, the effect of rating dispersion on sales could vary depending on the characteristics of the market. For instance, in niche markets where products have less awareness, disagreement of previous consumers' ratings could drive other consumers' curiosity, but in the major market, where most consumers recognize the products, it may not have the same effect in driving curiosity (Sun 2012).

Given the limitations of past studies, it seems clear that our understanding of the effect of rating dispersion requires enrichment. We accomplish this by addressing two research questions. First, we investigate the effect of rating dispersion specifically in the process of trial purchases of experience goods, carefully controlling for subtle differences in the effect across different products. Second, we clarify for which products rating dispersion is most important, identifying product characteristics 
that drive idiosyncrasy in the effect of rating dispersion.

For the empirical analyses, we collected daily movie box office data from the Korean Film Council (KFC, www.kofic.or.kr) and associated rating information from Naver Movies (movie. naver.com). Our data set covers top 75 movies with release times from January 2014 to December 2015, including 2,064 daily viewership observations and daily rating data. There are several interesting findings resulting from our empirical analyses. First, we found that major movie sales decrease with greater rating dispersion. This finding is consistent with the notion that rating dispersion is associated with the uncertainty regarding how well a product fits a customer's personal preference (Hong and Pavlou 2010, 2014; Kwark, Chen, and Raghunathan 2014). Second, this negative effect is more pronounced with greater rating volume. When there is a higher number of ratings, the observed rating dispersion better reflects the degree of inconsistency in product evaluation among all customers (Chintagunta et al. 2010; Nam, Manchanda, and Chintagunta 2010), thus revealing greater uncertainty about their fit with a product. Finally, the availability of additional information that mitigates uncertainty weakens the effect; specifically, the negative effect is reduced when the average rating is higher, brand power is greater, and release time is longer (Moore and Lehmann 1980; Shimp and Bearden 1982).

We make two key contributions to the literature. First, we establish the effect of rating dispersion on trial purchases of experience goods in rigorous empirical analyses where idiosyncrasies of the effects are considered. Our findings are consistent with a stream of research on risk aversion (Forsythe and Shi 2003; Hofstede and Bond 1984; Mandrik and Bao 2005) and emphasize the importance of dispersion in rating information. Second, we identify factors that induce differences in the influence of rating dispersion. Our findings not only enrich our understanding of the dispersion effect, but also narrow down for which products consistency of ratings is valued, which will be of interest to practitioners.

In the next sections, we first review previous research to elucidate the role of rating dispersion and propose our hypotheses. We then describe our data and variables for empirical study. Next, we present our analysis of the data and test the hypotheses. Finally, a conclusion and implications for academics and practitioners are provided, and the limitations of this study and future research directions are discussed.

\section{Theoretical Background and Hypotheses}

\subsection{The Effect of Rating Dispersion on Trials of Experience Goods}

Major online platforms provide information 
about individual customer ratings for experience goods to help consumers make more informed purchase decisions (Chen and Xie 2008; Qiu et al. 2012). Typically, rating information includes the number of customer ratings(volume), the score of the average rating (valence), and the dispersion of customer ratings.

Past studies have mainly examined the effects and distinct roles of rating volume and the valence of the average rating on sales (Chevalier and Mayzlin 2006; Chintagunta et al. 2010; Dellarocas et al. 2007; Duan et al. 2008a; Duan et al. 2008b; Liu 2006). Rating volume is known to be associated with awareness diffusion because exposure to a product increases when there are more reviews (Duan et al. 2008a; Godes and Mayzlin 2004; Liu 2006). In contrast, the valence of the average rating captures an aggregated evaluation of product quality (Chen, Wu, and Yoon 2004; Duan et al. 2008b; Schubert and Ginsburg 2000).

We expect that the dispersion of customers' ratings contains product information distinct from these two frequently studied factors. In this study, we examine three different types of uncertainty regarding experience goods (Hong and Pavlou 2010). First, description uncertainty is uncertainty about product characteristics; consumers seek information about product attributes in order to resolve this uncertainty. Second, performance uncertainty involves uncertainty regarding the ex-post performance of an experience product. Typically, the product's performance does not differ substantially from one customer to the next. Thus, it can be inferred from the valence of aggregate customer feedback such as the average rating and volume of the rating from previous customers. Third, customers may feel uncertain whether a product will fit their requirements, that is, their heterogeneous needs and wants. Rating dispersion reflects the degree to which opinions of different reviewers diverge in terms of product evaluation (Yin, Mitra, and Zhang 2016). Thus, this variable represents the degree of fit uncertainty.

Low dispersion indicates a fairly consistent product evaluation among previous customers. Given that there is a certain volume and valence of customer ratings, when the rating dispersion is low, fit uncertainty about the product is also low. In contrast, highly dispersed customer ratings indicate that evaluation of a product greatly depends on individual preference and therefore varies across different customers (Moe and Trusov 2011). The disagreements of previous consumers' evaluation drive other consumers' curiosity which can increase demand in niche markets (Sun 2012). In major markets, however, where consumers are more aware of products due to their media and communication exposure (Liu 2006), dispersed customer ratings might increase fit uncertainty.

Building upon the literature on risk aversion (Forsythe and Shi 2003; Hofstede and Bond 1984; Mandrik and Bao 2005: Matzler, GrabnerKräuter, and Bidmon 2008; Pavlou and Gefen 
2004), we expect that consumers will avoid purchasing a product for which they cannot determine their own likes and dislikes. Therefore, we propose the following hypothesis:

\section{H1: Rating dispersion has a negative effect} on product trial purchasing.

\subsection{The Effects of Rating Dispersion}

Although rating dispersion is distinct from other rating characteristics, its treatment in past studies has been mixed (Chintagunta et al. 2010; Clemons et al. 2006; Moe and Trusov 2011; Sun 2012; Zhu and Zhang 2010). To determine the effects of rating dispersion, we identify relevant variables and control for differential effects across different products, thus isolating the negative effects of rating dispersion and enriching our understanding about the nature of this variable. This study focuses on two groups of variables that may potentially moderate the effect of rating dispersion: other rating characteristics and product characteristics.

\subsection{Rating Dispersion and Other Rating Characteristics}

As noted earlier, rating volume is an important characteristic of aggregated rating that is known to drive awareness diffusion (Duan et al. 2008a; Liu 2006). In addition, rating volume also determines the overall reliability of rating information (Grewal, Gotlieb, and Marmorstein 1994: Harmon and Coney 1982). The notion is analogous to the "law of large number" in statistics (Bernoulli 1713). When rating volume is lower, the observed rating distribution may occur by chance, so it may not adequately reflect the true distribution of evaluation among all customers. When rating volume is larger, in contrast, the observed rating distribution will be closer to the true distribution of evaluation. Therefore, the rating distribution can be considered as more reliable when there is a higher number of ratings, and the negative effect of rating dispersion on trial purchases will be more salient when there is higher number of ratings. We therefore hypothesize as follows:

\section{H2: The negative effect of rating dispersion will be more pronounced when rating volume is high.}

Generally, the average rating measures the degree to which customers who have consumed a product actually like it. By construction, a high average rating will resolve performance uncertainty, which varies minimally across different customers (Garvin 1984). According to the utility model in which risk aversion is incorporated (e.g., the CARA utility function; see Bhardwaj 2001; Misra, Coughlan, and Narasimhan 2005: Narayanan and Manchanda 2009), there is an exponential relationship between the amount of uncertainty and disutility. 
To put it differently, the effect of fit uncertainty will be magnified when other types of uncertainty, such as that about a product's attributes and performance, are not resolved. In contrast, concern about unresolved fit uncertainty will be attenuated when there is compelling information about product attributes and performance (Misra et al. 2005; Narayanan and Manchanda 2009). We thus hypothesize the following about the compensatory effect of the average rating on rating dispersion:

\section{H3: The effect of rating dispersion will be} weakened when the valence of the average rating is high.

\subsection{Rating Dispersion and Product Characteristics}

We expect that the effect of rating dispersion on trial purchases will also be moderated by product characteristics related with description uncertainty. More specifically, we conjecture that the effect of rating dispersion will be attenuated for products with strong brand power, as information about a brand can resolve description uncertainty and signal the quality of products (Desai and Basuroy 2005; Levin, Levin, and Heath 1997; Wallace, Seigerman, and Holbrook 1993). For instance, consumers experiencing fit uncertainty about movies made by star actors, books written by big-name authors, and restaurants owned by star chefs will be less concerned because the strong reputation of those products resolves description uncertainty and would decrease other uncertainty. The claim is analogous to H3, and therefore we hypothesize the following about the effect of brand power on rating dispersion:

\section{H4. : The effect of rating dispersion will be weakened for products with stronger brand power.}

As time passes since the launch of a product, consumers gain access to rich and detailed information about product characteristics via sources other than online rating information (Bakshy et al. 2012; Bei, Chen, and Widdows 2004: Wellman, Boase, and Chen 2002). By processing this information, they can reduce fit uncertainty. For instance, consumers who share similar preferences may like the same movie (Brown and Reingen 1987; Ruef, Aldrich, and Carter 2003), and knowledge of each other's preferences may influence their decision-making about which movie to see. In addition, rating dispersion may simply contain information about the variation of evaluation, which will matter less if information from other sources is available. Accordingly, the effect of rating dispersion on product trial purchasing will decrease as time since the launch of a product increases. We therefore hypothesize as follows and present the research frame with Figure 1. 
〈Figure 1〉 Research Framework

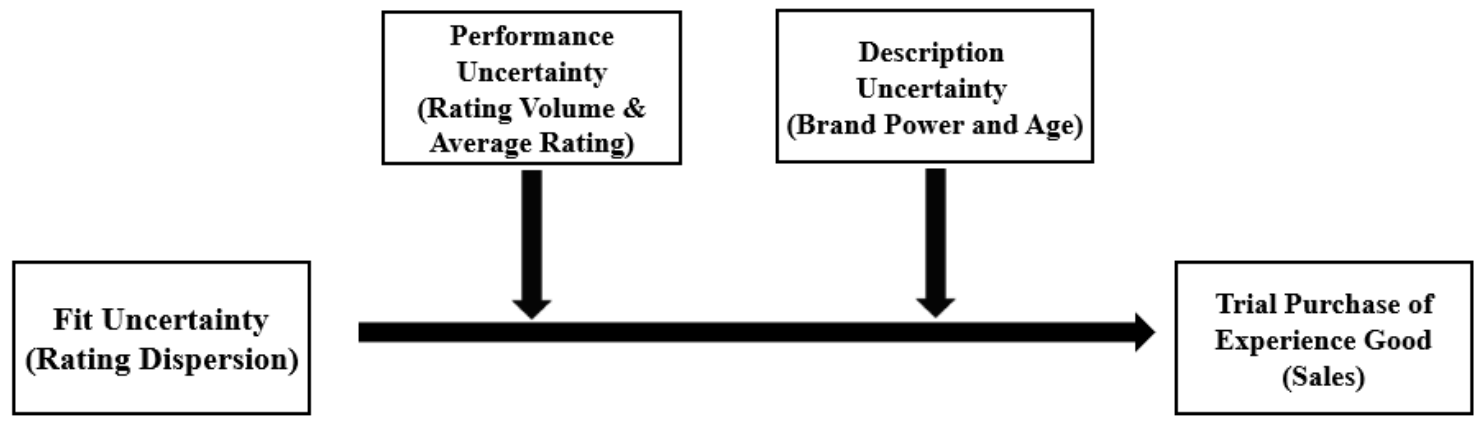

H5: The effect of rating dispersion will be weakened as the age of a product increases.

\section{Empirical Analyses}

In this section, we describe our empirical analyses. First, we outline the research setting and data collection process. Next, we explain how we construct our variables of interest. Then, we specify our empirical models and discuss the results.

\subsection{Research Setting and Data}

We collected data from the movie industry to investigate how rating dispersion influences consumers' purchase decision-making regarding new trials of experience goods. A movie is an experience good in that it is hard for consumers to determine whether they will like it before they actually watch it (Hong and Pavlou 2010). Thus, online movie ratings are an important information source for consumers. Many researchers have studied movie ratings (e.g., Duan et al. 2008b; Elberse and Eliashberg 2003; Liu 2006).

We collected data from two major sources. First, we collected detailed information about movies released between January 2014 and December 2015 from the Korea Film Council (KFC). The KFC is a government agency that supports the movie industry in South Korea and provides extensive information about movies, such as general movie characteristics (e.g., director, cast members, production/distribution company, genre), release information, and box office daily sales. After excluding movies running less than one week, we collected daily box office information for 383 domestic movies. We focus on domestic movies to control for any possible confounding effect between domestic and imported foreign movies. For instance, an imported movie can be released in domestic theaters after it has been released abroad. In 
this case, consumers may have acquired rich information about the movie even before its release in the domestic market.

Next, we collected movie rating information about the 383 movies from Naver Movies, which is the biggest movie review website in South Korea. Naver's portal site retains 42 million registered users (movie.naver.com). Like other review websites, enrolled users of Naver Movies rate a movie that they have watched on a scale of 1 to 10 points; members of the general public have access to those ratings and review information.

Naver Movies provides the ideal research setting to address our research questions for the following reasons. First, a variety of rating information about movies is presented on its webpage. As shown in Figure 2, one can clearly see the average rating, summarized as the cumulative arithmetic mean up to the current day, and the rating volume, counted as the cumulative number of reviews in total. Moreover, one can check the cumulative rating dispersion visually via the rating histogram. This is consistent with our premise that consumers have access to information regarding rating dispersion. Second, the website has reliable rating information. According to the terms of Naver Movies, only enrolled users of the website who log in with verified ID can post reviews on Naver Movies. Also, a user can post only one review for a specific movie, thus avoiding redundancy in the reviews. For the purposes of this study, we can be sure that the ratings and reviews have not been manipulated intentionally by certain individuals or movie stakeholders, but that the feedback from people who have watched the movie is real and credible (Bae and Kim 2013; Yang et al. 2012; Zhang, Choi, and Lee 2017).

There is a huge variation in the number of ratings among the 383 movies (from 0 to 64,146). The distribution, obviously, is right-skewed. To boost the stability and reliability of the results of the analyses, therefore, we conduct our empirical analyses on 75 movies, the upper $20 \%$ of movies with the highest number of ratings (Chintagunta et al. 2010). Since the bottom $80 \%$ of movies have ratings less than 2500 and have a short and small screen share, the dispersion of ratings with low awareness can trigger consumer curiosity, thus we excluded this data to avoid confounding effects of rating dispersion between curiosity and fit uncertainty. For our movie sample, we eliminate the right tail of viewership data if the daily screen rate drops down to $3 \%$ because this covers most of the interesting periods for the movies included in our sample (see also Duan et al. 2008b; Liu 2006). We merged data for the movie characteristics of these 75 movies, daily viewership data from the day of release to the end of the life cycle, and cumulative rating information that consumers see each day. As a result of this elimination process, 2,064 observations make up the major data set for our analyses. 
〈Figure 2〉 Rating Information Example on Naver Movies
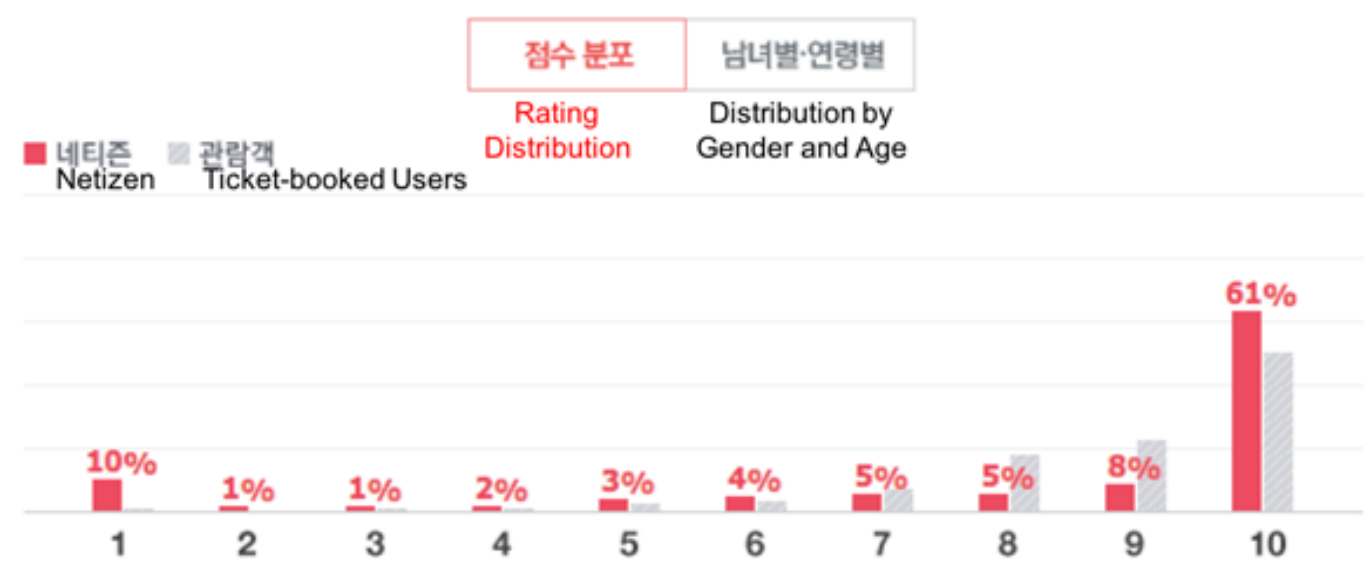

\subsection{Variables}

In our empirical analyses, box office sales is the key variable of interest. We define Viewer as the number of viewers (i.e., box office sales) of movie $i$ at time $t$. In our analyses, we assume that the number of consumers who watch the same movie at movie theaters multiple times is very small.

Next, we construct measures for three characteristics of ratings: rating volume, overall valence of the average rating, and rating dispersion based on cumulative rating information. These measures correspond exactly to what is presented on the website. CUMVolume it-I denotes the cumulative number of ratings of movie $i$ by time $t-1$. CUMRating it $-1_{1}$ denotes the average of cumulative individual ratings of movie $i$ posted by day $t-1$. By definition, CUMRating $_{i t-1}$ is a metric for the valence of the average rating. CUMDisper it $-1^{\text {denotes the }}$ overall degree of dispersion of individual ratings of movie $i$ posted by day $t-1$. Although this dispersion metric is not directly displayed on the website, consumers can infer it via the rating histogram. As a proxy for perceived dispersion of ratings, we use standard deviation and variance, which are widely-used metrics of dispersion (i.e., the greater the standard deviation and variance, the more dispersed the ratings).

We hypothesize that the effect of rating dispersion will be moderated by two product characteristics: brand power and product age since launch. The time-invariant variable Star $_{i}$ denotes the star power of movie $i$; star power in the movie industry is a known analog of brand power because popular movie actors have name recognition, certain images, and associations with particular types of products like popular brands (Levin et al. 1997). Similar to previous studies (Basuroy, Desai, and Talukdar 
2006; Litman 1983), we measure star power as the total number of awards and nominations received by the actors/actresses and director in prior years (i.e., before the release of the movie being studied). The variable $A g e_{i t}$ is the age of movie $i$ at time $t$, which captures the natural time trend of the product life cycle. We measure $A g e_{i t}$ in days because movies have relatively shorter life cycles than other products.

We use several variables in our analyses to control for the heterogeneous characteristics of movies. The variable Prod $_{i}$ is an indicator that equals 1 if movie $i$ is produced by the three film companies that possess their own cinemas (i.e., CJ, Lotte, and Megabox Entertainment); the variable Dist $_{i}$ is set to 1 if movie $i$ is distributed by the three film companies listed above, and 0 otherwise. We also have Genre, which takes a value of 1 for movies in the five main movie genres (i.e., action, adventure, comedy, drama, and romance; see also Yang et al. 2012), and 0 otherwise. The variables defined above are used to control for the effect of movie attributes. In addition, we include a variable called Weekend, which takes a value of 1 if the movie is viewed on a Friday, Saturday, or Sunday (Duan et al. 2008a). We also include a monthly dummy variable for the release dates of movies (i.e., Jan, Febi, $\cdots$ Deci $_{i}$ ). Descriptive statistics of these variables are presented in Table 1.

\subsection{Empirical Model}

Our empirical model is specified as follows.

〈Table 1〉 Descriptive Statistics

\begin{tabular}{lcccc}
\hline \multicolumn{1}{c}{ Variable } & Mean & SD & Min & Max \\
\hline Viewer & 96,780 & $139,064.1$ & 1,078 & $1,257,380$ \\
CUMDisper (Standard Deviation) & 2.619 & 0.639 & 0.644 & 4.136 \\
CUMDisper (Variance) & 7.266 & 3.367 & 0.414 & 17.104 \\
CUMVolume & 8,033 & $9,839.843$ & 53 & 53,973 \\
CUMRating & 8.158 & 0.834 & 5.833 & 9.867 \\
Star & 55.24 & 38.629 & 0 & 183 \\
Age & 17.91 & 14.162 & 1 & 80 \\
Prod & 0.059 & 0.235 & 0 & 1 \\
Dist & 0.571 & 0.495 & 0 & 1 \\
Genre & 0.607 & 0.489 & 0 & 1 \\
Weekend & 0.426 & 0.495 & 0 & 1 \\
\hline
\end{tabular}

Notes. Values are computed on 2,064 observations. The descriptive statistics of month dummies are not reported to avoid clutter. 
Viewer $_{i t}=\alpha_{i}+\beta_{i t}$ CUMDisper $_{i t-1}+\gamma Z_{i t}+\varepsilon_{i t}$

$$
\text { where } \varepsilon_{i t} \sim N\left(0, \sigma^{2}\right)
$$

$a_{i}$ in Equation (1) is the movie-specific intercept. $\beta_{i t}$ is the impact of rating dispersion, our variable of interest. As stated earlier, we allow the effect of rating dispersion to vary by movie and time. The row vector $Z_{\text {it }}$ contains the time-variant covariates that may influence movie viewership. It includes all the timevarying independent variables that were introduced earlier (i.e., CUMVolume ${ }_{i t-1}$, CUMRating ${ }_{i t-1}$, Age $_{\text {it }}$, and $W_{\text {eekend }}$ ). In addition, $Z_{\text {it }}$ includes Viewer $_{\text {it-1 }}$, the lagged viewership. This is to control for time-varying heterogeneity in box office sales (Iyengar, Van den Bulte, and Lee 2015). The coefficient associated with $Z_{\text {it }}$ is denoted by $\gamma$. The error term $\varepsilon_{\text {it }}$ is assumed to follow a normal distribution, with zero as its mean and $\sigma^{2}$ as its variance.

Specifically, the movie-specific intercept and movie-time specific slope are defined as the mixed effect in Equation (2).

$$
\begin{aligned}
\alpha_{i}= & \alpha_{0}+\alpha_{1} X_{i}+\eta_{i t} \\
\beta_{i t}= & \beta_{0}+\beta_{1} \text { CUMVOlume }_{i t-1}+\beta_{2} \text { CUMRating }_{i t-1} \\
& +\beta_{3} \text { Star }_{i}+\beta_{4} \text { Age }_{i t}+\eta_{\beta i} \\
& \text { where }\left[\begin{array}{l}
\eta_{\alpha \mathrm{i}} \\
\eta_{\beta \mathrm{i}}
\end{array}\right] \sim \mathrm{N}\left(\left[\begin{array}{l}
0 \\
0
\end{array}\right],\left[\begin{array}{cc}
\sigma_{\mathrm{a}}^{2} & \mathrm{r} \sigma_{\mathrm{a}} \sigma_{\beta} \\
\mathrm{r} \sigma_{\mathrm{a}} \sigma_{\beta} & \sigma_{\beta}^{2}
\end{array}\right]\right)
\end{aligned}
$$

The movie-specific intercept, $a_{i}$ consists of three parts: a general intercept $a_{0}$, the time- invariant movie characteristics vector $X_{i}$ and its corresponding parameters $a_{1}$, and the moviespecific random effect $\eta_{\text {ai }}$. The time-invariant movie characteristics vector $\mathrm{X}_{\mathrm{i}}$ includes $\mathrm{Star}_{\mathrm{i}}$, $\operatorname{Prod}_{\mathrm{i}}$, Dist $_{\mathrm{i}}$, Genre, and a monthly dummy for release date.

Similarly, the effect of rating dispersion, $\beta_{i t}$, is composed of the main effect parameter $\beta_{0}$ and the moderating effects of other rating information (rating volume and average rating) and movie characteristics (brand power and movie age), which are captured in $\beta_{1}$ to $\beta_{4}$ respectively, and the random movie-specific dispersion effect $n_{\beta i}$. Finally, the movie-specific random intercept and slope are assumed to follow normal distributions and allowed to be correlated as in Equation (2).

\subsection{Results}

We ran six different models to test our hypotheses and check the robustness of the findings. In Models 1 - 3, we define CUMDisper ${ }_{i t}$ as the standard deviation of cumulative ratings on movie $i$ posted by day $t$. More specifically, Model 1 is a basic model with no random effects (i.e., $\eta_{a i}=n_{\beta i}=0$ ). Model 2 is a model with the random intercept only (i.e., $n_{\beta i}$ $=0)$. Finally, Model 3 is a full model as Equation (2) is specified. In Models $4-6$, we define CUMDisperit as the variance of cumulative ratings, and the specification of each model is analogous to Models 1 to 3 . The results are 
$\langle$ Table 2〉 Estimation Results

\begin{tabular}{|c|c|c|c|c|c|c|}
\hline \multirow[b]{2}{*}{ Variables } & \multicolumn{3}{|c|}{ Disper $_{i t}:$ Standard Deviation } & \multicolumn{3}{|c|}{ Disper $_{i t}:$ Variance } \\
\hline & Model 1 & Model 2 & Model 3 & Model 4 & Model 5 & Model 6 \\
\hline Intercept $\left(\alpha_{0}\right)$ & $\begin{array}{c}3.590^{* * *} \\
(0.231)\end{array}$ & $\begin{array}{c}4.697^{* * *} \\
(0.277)\end{array}$ & $\begin{array}{c}4.735^{* * *} \\
(0.278)\end{array}$ & $\begin{array}{l}3.513^{* * *} \\
(0.0227)\end{array}$ & $\begin{array}{c}4.698^{* * *} \\
(0.276)\end{array}$ & $\begin{array}{c}4.723^{* * *} \\
(0.275)\end{array}$ \\
\hline CUMDisper ${ }_{i t-1}\left(\beta_{0}\right)$ & $\begin{array}{c}-0.525^{* * *} \\
(0.115)\end{array}$ & $\begin{array}{c}-0.506^{* * *} \\
(0.150)\end{array}$ & $\begin{array}{c}-0.528^{* * *} \\
(0.154)\end{array}$ & $\begin{array}{c}-0.095^{* * *} \\
(0.021)\end{array}$ & $\begin{array}{c}-0.098^{* * *} \\
(0.027)\end{array}$ & $\begin{array}{c}-0.102 * * * \\
(0.028)\end{array}$ \\
\hline CUMDisper $_{i t-1} \times$ CUMVolume $_{i t-1}\left(\beta_{1}\right)$ & $\begin{array}{c}-0.152^{* * *} \\
(0.029)\end{array}$ & $\begin{array}{c}-0.187^{* * *} \\
(0.040)\end{array}$ & $\begin{array}{c}-0.199^{* * *} \\
(0.042)\end{array}$ & $\begin{array}{c}-0.029^{* * *} \\
(0.006)\end{array}$ & $\begin{array}{c}-0.038^{* * *} \\
(0.008)\end{array}$ & $\begin{array}{c}-0.040 * * * \\
(0.008)\end{array}$ \\
\hline CUMDisper $_{i t-1} \times$ CUMRating $_{i t-1}\left(\beta_{2}\right)$ & $\begin{array}{c}0.120^{* * *} \\
(0.024)\end{array}$ & $\begin{array}{l}0.095^{*} \\
(0.041)\end{array}$ & $\begin{array}{l}0.090^{*} \\
(0.045)\end{array}$ & $\begin{array}{c}0.014^{* * *} \\
(0.004)\end{array}$ & $\begin{array}{l}0.014^{*} \\
(0.007)\end{array}$ & $\begin{array}{c}0.013 \\
(0.007)\end{array}$ \\
\hline CUMDisper $_{i t-1} \times \operatorname{Star}_{i}\left(\beta_{3}\right)$ & $\begin{array}{c}0.104^{* * *} \\
(0.021)\end{array}$ & $\begin{array}{l}0.111^{* *} \\
(0.037)\end{array}$ & $\begin{array}{c}0.115^{*} \\
(0.046)\end{array}$ & $\begin{array}{c}0.020^{* * *} \\
(0.004)\end{array}$ & $\begin{array}{l}0.023^{* *} \\
(0.008)\end{array}$ & $\begin{array}{c}0.024^{*} \\
(0.009)\end{array}$ \\
\hline CUMDisper $_{i t-1} \times \operatorname{Age}_{i t}\left(\beta_{4}\right)$ & $\begin{array}{l}0.077^{*} \\
(0.034)\end{array}$ & $\begin{array}{l}0.101^{*} \\
(0.040)\end{array}$ & $\begin{array}{l}0.110^{* *} \\
(0.042)\end{array}$ & $\begin{array}{l}0.0139^{*} \\
(0.006)\end{array}$ & $\begin{array}{l}0.021^{* *} \\
(0.008)\end{array}$ & $\begin{array}{l}0.022^{* *} \\
(0.008)\end{array}$ \\
\hline CUMVolume $_{i t-1}$ & $\begin{array}{c}0.272^{* * *} \\
(0.024)\end{array}$ & $\begin{array}{c}0.361^{* * *} \\
(0.035)\end{array}$ & $\begin{array}{c}0.368^{* * *} \\
(0.035)\end{array}$ & $\begin{array}{c}0.264^{* * *} \\
(0.023)\end{array}$ & $\begin{array}{c}0.362^{* * *} \\
(0.035)\end{array}$ & $\begin{array}{c}0.367^{* * *} \\
(0.035)\end{array}$ \\
\hline CUMRating $i t-1$ & $\begin{array}{l}-0.084 \\
(0.047)\end{array}$ & $\begin{array}{l}-0.001 \\
(0.081)\end{array}$ & $\begin{array}{l}-0.001 \\
(0.082)\end{array}$ & $\begin{array}{l}-0.071 \\
(0.045)\end{array}$ & $\begin{array}{c}0.007 \\
(0.077)\end{array}$ & $\begin{array}{c}0.005 \\
(0.078)\end{array}$ \\
\hline $\operatorname{Star}_{i}$ & $\begin{array}{c}0.008 \\
(0.019)\end{array}$ & $\begin{array}{c}-0.001 \\
(0.035)\end{array}$ & $\begin{array}{c}0.002 \\
(0.037)\end{array}$ & $\begin{array}{c}0.003 \\
(0.018)\end{array}$ & $\begin{array}{c}-0.006 \\
(0.035)\end{array}$ & $\begin{array}{c}-0.001 \\
(0.037)\end{array}$ \\
\hline Age $_{i t}$ & $\begin{array}{c}-0.539^{* * *} \\
(0.037)\end{array}$ & $\begin{array}{c}-0.694^{* * *} \\
(0.046)\end{array}$ & $\begin{array}{c}-0.702^{* * *} \\
(0.046)\end{array}$ & $\begin{array}{c}-0.529^{* * *} \\
(0.036)\end{array}$ & $\begin{array}{c}-0.696^{* * *} \\
(0.046)\end{array}$ & $\begin{array}{c}-0.701^{* * *} \\
(0.046)\end{array}$ \\
\hline Viewer $_{i t-1}$ & $\begin{array}{c}0.771^{* * *} \\
(0.013)\end{array}$ & $\begin{array}{c}0.711^{* * *} \\
(0.014)\end{array}$ & $\begin{array}{c}0.708^{* * * *} \\
(0.014)\end{array}$ & $\begin{array}{c}0.774^{* * * *} \\
(0.013)\end{array}$ & $\begin{array}{c}0.710^{* * * *} \\
(0.014)\end{array}$ & $\begin{array}{c}0.708 * * * \\
(0.014)\end{array}$ \\
\hline Prod $_{i}$ & $\begin{array}{c}0.082 \\
(0.048)\end{array}$ & $\begin{array}{c}0.138 \\
(0.108)\end{array}$ & $\begin{array}{c}0.158 \\
(0.117)\end{array}$ & $\begin{array}{c}0.083 \\
(0.048)\end{array}$ & $\begin{array}{c}0.150 \\
(0.111)\end{array}$ & $\begin{array}{c}0.170 \\
(0.120)\end{array}$ \\
\hline Dist $_{i}$ & $\begin{array}{l}-0.021 \\
(0.021)\end{array}$ & $\begin{array}{l}-0.045 \\
(0.044)\end{array}$ & $\begin{array}{l}-0.043 \\
(0.045)\end{array}$ & $\begin{array}{l}-0.021 \\
(0.021)\end{array}$ & $\begin{array}{l}-0.045 \\
(0.045)\end{array}$ & $\begin{array}{l}-0.044 \\
(0.045)\end{array}$ \\
\hline Genre $_{i}$ & $\begin{array}{l}0.063^{* *} \\
(0.023)\end{array}$ & $\begin{array}{c}0.055 \\
(0.048)\end{array}$ & $\begin{array}{c}0.055 \\
(0.049)\end{array}$ & $\begin{array}{l}0.063^{* *} \\
(0.023)\end{array}$ & $\begin{array}{c}0.059 \\
(0.049)\end{array}$ & $\begin{array}{c}0.059 \\
(0.049)\end{array}$ \\
\hline Weekendt $_{t}$ & $\begin{array}{c}0.555^{* * *} \\
(0.019)\end{array}$ & $\begin{array}{c}0.555^{* * *} \\
(0.018)\end{array}$ & $\begin{array}{c}0.555^{* * *} \\
(0.018)\end{array}$ & $\begin{array}{c}0.554^{* * *} \\
(0.019)\end{array}$ & $\begin{array}{c}0.555^{* * *} \\
(0.018)\end{array}$ & $\begin{array}{c}0.555^{* * *} \\
(0.018)\end{array}$ \\
\hline LL & -1016.4 & -1010.2 & -1008.1 & -1017.5 & -1010.1 & -1008.6 \\
\hline BIC & 2238.0 & 2233.0 & 2244.0 & 2240.1 & 2232.8 & 2245.1 \\
\hline
\end{tabular}

Notes. Standard errors in parentheses. Following prior studies (Liu 2006: Duan et al. 2008b), we log-transform count variables including Viewer, CUMVolume, Star, and Age. The variables CUMDisper, CUMVolume, CUMRating, Star, and Age are mean-centered before estimation. We exclude the observations of Viewerit on the first day because there are no lag values for the independent variables $(N=1,989)$. The results of the eleven-month dummies are not reported to avoid clutter.

$* \mathrm{p}<0.05 ; * * \mathrm{p}<0.01 ; * * * \mathrm{p}<0.001$. 
shown in Table 2; the results are highly robust across all six models. For the hypotheses testing and interpretation, however, we focus only on Model 5 because it has the lowest BIC value (Model 5).

There are several interesting findings. First, rating dispersion generally has a negative effect on movie viewership, consistent with $\mathrm{H} 1 \quad\left(\beta_{0}=\right.$ $-0.098, p<.001)$. We incorporated idiosyncrasy in testing of the effect, and our finding implies that higher rating dispersion reduces movie viewership when all else is equal. A unit increase in rating dispersion results in a $9.8 \%$ decrease in movie viewership. This finding is not only appealing to our intuition, but also consistent with previous research on fit uncertainty and risk aversion (Hong and Pavlou 2010, 2014; Forsythe and Shi 2003; Hofstede and Bond 1984; Mandrik and Bao 2005).

Second, the negative dispersion effect magnifies when rating volume increases $\left(\beta_{1}=-0.038\right.$, $p<.001)$. All else being equal, a 1\% increase in volume results in a 3.8\% further decrease in movie viewership per unit increase in rating dispersion. This is consistent with our claim in $\mathrm{H} 2$ that higher rating volume boosts the credibility of aggregated rating information, making concerns about fit uncertainty more salient for potential customers.

Third, the negative effect of rating dispersion is attenuated when there is additional information that can mitigate fit uncertainty. Specifically, the effect of rating dispersion is weakened when the valence of the average rating is high $\left(\beta_{2}=0.014, p<.05\right)$, supporting H3. A unit increase in average rating results in a $1.4 \%$ lower decrease in the rating dispersion effect in movie viewership per unit increase in rating dispersion. This can be explained by the utility model incorporating risk aversion as follows: consumers' concerns about unresolved fit uncertainty are alleviated when uncertainty about product attributes and performance is resolved.

As expected in H4, the negative effect of rating dispersion on movie viewership is attenuated when brand power is strong $\left(\beta_{3}=\right.$ $0.023, p<.01)$. A $1 \%$ increase in brand power leads to a $2.3 \%$ lower decrease in movie viewership per unit increase in rating dispersion. Strong brand power resolves attribute uncertainty and signals the quality of products as well.

Moreover, the effect of rating dispersion decreases as time passes since the launch of a product $\left(\beta_{4}=0.021, p<.01\right)$. A $1 \%$ increase in age leads to a $2.1 \%$ lower decrease in movie viewership per unit increase in rating dispersion. Consumers can better determine their likes and dislikes using rich and detailed information via alternative sources as time goes on.

Estimates for the control variables replicate findings from prior research and support the face validity of our key findings. Rating volume has a significant positive effect on future movie viewership $(p<.001)$, while the valence of the average rating $(p<.1)$ does not influence movie viewership significantly (see also Liu 
2006: Duan et al. 2008a). The box office sales of a movie $i$ decrease over time since its release ( $p<.001)$ (see also Duan et al. 2008b; Chintagunta et al. 2010). Not surprisingly, there is high state dependence in movie sales $(p<.001)$. Weekends also have significantly higher viewership than weekdays $(p<.001)$, which is also consistent with past studies (Duan et al. 2008a).

\section{Conclusion}

In this paper, we investigate the effect of rating dispersion on movie viewership and identify the conditions under which the effect of rating dispersion is intensified or reduced in a major market. There are three prominent findings. First, movie sales decrease as movie ratings become more dispersed. This finding is consistent with the notion that rating dispersion is associated with fit uncertainty, the uncertainty regarding how well a product will fit consumers' requirements and heterogeneous needs and wants (Hong and Pavlou 2010). Second, the negative effect is more pronounced when rating volume is higher. High rating volume is associated with a more reliable rating distribution and thus better reflects the degree of inconsistency in product evaluation among all customers (Chintagunta et al. 2010; Nam et al. 2010). Finally, we find a weaker negative effect of rating dispersion in conditions where additional information that can mitigate the uncertainty is available. Specifically, the effect is reduced when the average rating is higher, brand power is greater, and the time since the release is long (Moore and Lehmann 1980; Shimp and Bearden 1982).

\subsection{Implications for Researchers}

The results of our empirical analysis reveal the general effect of rating dispersion on trials of experience goods and have several implications for researchers. First, we show that rating dispersion is an important type of rating information associated with fit uncertainty. Prior research has mainly focused on rating volume and the valence of the average rating (Duan et al. 2008a; Chintagunta et al. 2010; Liu 2006). We suggest that future researchers on rating information should consider rating dispersion as well. Failure to incorporate rating dispersion can lead to over- or underestimates of the impact of ratings. Moreover, other characteristics, such as the consistency of sequential ratings (Purnawirwan, Pelsmacker, and Dens 2012) or skewness (Hurley and Estelami 1998), may also be of interest to researchers.

Second, we confirm the negative effect of rating dispersion in a rigorous empirical study. Previous research presented inconsistent findings on rating dispersion due to differences in context and lack 
of control over heterogeneous sensitivity to rating dispersion across different products. After controlling for heterogeneity of the dispersion effect in the context of trial purchasing of experience goods, we found rating dispersion to have a negative effect on product sales in this study. This finding is robust across several different models and subject to rigorous specifications, which is also consistent with a stream of research on fit uncertainty and risk aversion. In future research, it will be interesting to see what role rating dispersion plays in other contexts such as the repeat purchase of experience goods or trial purchase of search goods.

Third, we examine several variables that moderate the effect of rating dispersion. Specifically, we focus on the reliability of rating dispersion and additional information that can mitigate the salience of fit uncertainty. We expect that various factors moderate the effect of rating dispersion in addition to the variables we mentioned above. For instance, the website providing the rating information may be one such factor (Lee and Youn 2009). That is, rating dispersion from a third-party website may be more reliable than that from a commercial website. Our understanding of the role of rating information will be enriched if we learn more about the factors that can moderate the rating effect.

\subsection{Implications for Practitioners}

Our findings have significant implications for practitioners as well. Our findings show that concern about fit uncertainty increases as ratings become more dispersed. However, the rating dispersion effect can be attenuated when additional information, which can moderate consumers' fit uncertainty, is provided. Thus, managers can utilize this additional information to reduce the negative effect of rating dispersion. When movie evaluations vary significantly, for instance, stakeholders can consider releasing trailers or utilizing various online content to solicit consumer feedback, release authoritative third-party information, and experience simulation (Huang et al. 2009). For other experience goods with high rating dispersion, new technologies that enable consumers to touch and feel products, such as augmented reality (AR), may help significantly increase sales by reducing fit uncertainty.

In addition, our research has implications for review manipulation as well. Amazon.com defines review manipulation as "any attempt by sellers or manufacturers to gain unfair advantages by creating false, misleading or inauthentic feedback about products or services". ${ }^{1)}$ In addition to discussions about ethical correctness, there have been long debates to determine the pros and cons of review manipulation on the Internet

1) https://www.xsellco.com/resources/avoid-review-manipulation-amazon/. 
(Gössling, Hall, and Andersson 2018; Hu et al. 2012; Mayzlin, Dover, and Chevalier 2014). Our findings on the effect of rating dispersion imply that review manipulation may dampen product sales because manipulated high-rating reviews are not often consistent with true reviews of actual customers; in fact, they generally increase rating dispersion as well as fit uncertainty.

\subsection{Limitations}

Our study also has a few limitations. First, we focus solely on rating information in this study. Cumulative rating information is an overall summary of consumers' ratings. By contrast, an individual review may include richer and more detailed evaluation of the product. We suggest that research on the text of reviews using big data analysis or content analysis may offer a richer understanding of consumers' review-browsing behavior. For example, even within the same set of five-star reviews, the message text itself may differ in terms of degree of enthusiasm (Chevalier and Mayzlin 2006). It will be interesting to see whether the effect of dispersion in review texts differs from the effect of dispersion in ratings.

Second, Naver Movie is a single-dimensional rating system. Some online platforms, such as TripAdvisor, have introduced multidimensional rating systems to incorporate ratings of different product dimensions (Chen, Hong, and Liu 2017). For instance, the evaluation of a restaurant may not only be based on overall performance, but also on some very specific dimensions such as taste and service. Multidimensional rating systems help consumers better determine the fit between a product and themselves. Thus, how dispersion works in a multidimensional rating system is another future topic of study for researchers.

Third, we investigated the effect of rating dispersion on movie viewership based on a one-day interval. However, the act of watching movies is continuously happening. If we were able to analyze movie viewership using a subtler time unit, it would be possible to compare the immediate and long-term effects of rating dispersion more rigorously.

Finally, our rating data is collected from Naver Movie, a popular movie review website in South Korea. We thus could not control for the unique effects of the specific display pattern and the predetermined group of users of the website. Incorporating data from other websites may help establish more reliable results.

〈Received January 7. 2019〉

〈Accepted April 26. 2019〉

\section{References}

Bae, J., \& Kim, B. D. (2013). Is the electronic word of mouth effect always positive on the movie?, Academy of Marketing Studies 
Journal, 17 (1), 61-78.

Bakshy, E., Rosenn, I., Marlow, C., \& Adamic, L. (2012). The role of social networks in information diffusion, In Proceedings of the 21st international conference on World Wide Web, 519-28. ACM.

Basuroy, S., Desai, K. K., \& Talukdar, D. (2006). An empirical investigation of signaling in the motion picture industry. Journal of Marketing Research, 43 (2), 287-295.

Bei, L. T., Chen, E. Y., \& Widdows, R. (2004). Consumers' online information search behavior and the phenomenon of search vs. experience products, Journal of Family and Economic Issues, 25 (4), 449-467.

Bernoulli, J. (1713). Ars conjectandi. Impensis Thurnisiorum, fratrum.

Bhardwaj, P. (2001). Delegating pricing decisions, Marketing Science, 20 (2), 143-169.

Brown, J. J., \& Reingen, P. H. (1987). Social ties and word-of-mouth referral behavior, Journal of Consumer Research, 14 (3), 350-362.

Chen, P. Y., Hong, Y., \& Liu, Y. (2017). The value of multidimensional rating systems: Evidence from a natural experiment and randomized experiments, Management Science, 64 (10), 4629-4647.

Chen, P. Y., Wu, S. Y., \& Yoon, J. (2004). The impact of online recommendations and consumer feedback on sales, ICIS 2004 Proceedings, 58, 711-724.

Chen, Y., \& Xie, J. (2008). Online consumer review: Word-of-mouth as a new element of marketing communication mix, Management Science, 54 (3), 477-91.

Chevalier, J. A., \& Mayzlin, D. (2006). The effect of word of mouth on sales: Online book reviews, Journal of Marketing Research, 43(3), 345-354.

Chintagunta, P. K., Gopinath, S., \& Venkataraman, S. (2010). The effects of online user reviews on movie box office performance: Accounting for sequential rollout and aggregation across local markets, Marketing Science, 29 (5), 944-957.

Clemons, E. K., Gao, G. G., \& Hitt, L. M. (2006). When online reviews meet hyperdifferentiation: A study of the craft beer industry, Journal of Management Information Systems, 23 (2), 149-171.

Dellarocas, C., Zhang, X. M., \& Awad, N. F. (2007). Exploring the value of online product reviews in forecasting sales: The case of motion pictures, Journal of Interactive Marketing, 21 (4), 23-45.

Desai, K. K., \& Basuroy, S. (2005). Interactive influence of genre familiarity, star power, and critics' reviews in the cultural goods industry: The case of motion pictures, Psychology \& Marketing, 22 (3), 203-223.

Duan, W., Gu, B., \& Whinston, A. B. (2008a). Do online reviews matter?-An empirical investigation of panel data, Decision Support Systems, 45(4), 1007-1016.

Duan, W., Gu, B., \& Whinston, A. B. (2008b). 
The dynamics of online word-of-mouth and product sales - An empirical investigation of the movie industry, Journal of Retailing, 84 (2), 233-242.

Elberse, A., \& Eliashberg, J. (2003). Demand and supply dynamics for sequentially released products in international markets: The case of motion pictures, Marketing Science, 22 (3), 329-354.

Forsythe, S. M., \& Shi, B. (2003). Consumer patronage and risk perceptions in Internet shopping, Journal of Business Research, 56 (11), 867-875.

Garvin, D. A. (1984). What does "product quality" really mean?, Sloan Management Review, 3, 25-43.

Godes, D., \& Mayzlin, D. (2004). Using online conversations to study word-of-mouth communication, Marketing Science, 23 (4), 545-560.

Gössling, S., Hall, C. M., \& Andersson, A. C. (2018). The manager's dilemma: a conceptualization of online review manipulation strategies, Current Issues in Tourism, 21 (5), 484-503.

Grewal, D., Gotlieb, J., \& Marmorstein, H. (1994). The moderating effects of message framing and source credibility on the price-perceived risk relationship, Journal of Consumer Research, 21 (1), 145-153.

Harmon, R. R., \& Coney, K. A. (1982). The persuasive effects of source credibility in buy and lease situations, Journal of Marketing
Research, 19 (2), 255-260.

Harrison-Walker, L. J. (2001). The measurement of word-of-mouth communication and an investigation of service quality and customer commitment as potential antecedents, Journal of Service Research, 4 (1), 60-75. Hurley, R. F., \& Estelami, H. (1998). Alternative indexes for monitoring customer perceptions of service quality: A comparative evaluation in a retail context, Journal of the Academy of Marketing Science, 26 (3), 209-221.

Hofstede, G., \& Bond, M. H. (1984). Hofstede's culture dimensions: An independent validation using Rokeach's value survey, Journal of Cross-cultural Psychology, 15 (4), 417-433. Hong, Y., \& Pavlou, P. A. (2010). Fit does matter! An empirical study on product fit uncertainty in online marketplaces, ICIS 2010 Proceedings, 218, 1-20.

Hong, Y., \& Pavlou, P. A. (2014). Product fit uncertainty in online markets: Nature, effects, and antecedents. Information Systems Research, 25 (2), 328-344.

Hu, N., Bose, I., Koh, N. S., \& Liu, L. (2012). Manipulation of online reviews: An analysis of ratings, readability, and sentiments, Decision Support Systems, 52 (3), 674-684. Huang, P., Lurie, N. H., \& Mitra, S. (2009). Searching for experience on the web: An empirical examination of consumer behavior for search and experience goods, Journal of Marketing, 73 (2), 55-69.

Iyengar, R., Van den Bulte, C., \& Lee, J. Y. 
(2015). Social contagion in new product trial and repeat, Marketing Science, 34 (3), 408-429.

Kwark, Y., Chen, J., \& Raghunathan, S. (2014). Online product reviews: Implications for retailers and competing manufacturers, Information Systems Research, 25 (1), 93-110.

Lee, M., \& Youn, S. (2009). Electronic word of mouth (eWOM) How eWOM platforms influence consumer product judgement, International Journal of Advertising, 28 (3), 473-499.

Levin, A. M., Levin, I. P., \& Heath, C. E. (1997). Movie stars and authors as brand names: Measuring brand equity in experiential products, in NA - Advances in Consumer Research 24 eds., 175-181.

Litman, B. R. (1983). Predicting success of theatrical movies: An empirical study, The Journal of Popular Culture, 16 (4), 159-175.

Liu, Y. (2006). Word of mouth for movies: Its dynamics and impact on box office revenue, Journal of Marketing, 70 (3), 74-89.

Mandrik, C. A., \& Bao, Y. (2005). Exploring the concept and measurement of general risk aversion, in NA - Advances in Consumer Research Volume 32, eds., 531-539.

Matzler, K., Grabner-Kräuter, S., \& Bidmon, S. (2008). Risk aversion and brand loyalty: the mediating role of brand trust and brand affect, Joumal of Product and Brand Management, 17 (3), 154-162.
Mayzlin, D., Dover, Y., \& Chevalier, J. (2014). Promotional reviews: An empirical investigation of online review manipulation, American Economic Review, 104 (8), 2421-2455.

Misra, S., Coughlan, A. T., \& Narasimhan, C. (2005). Salesforce compensation: An analytical and empirical examination of the agency theoretic approach, Quantitative Marketing and Economics, 3 (1), 5-39.

Moe, W. W., \& Trusov, M. (2011). The value of social dynamics in online product ratings forums, Journal of Marketing Research, 48 (3), 444-456.

Moore, W. L., \& Lehmann, D. R. (1980). Individual differences in search behavior for a nondurable, Journal of Consumer Research, 7 (3), 296-307.

Nam, S., Manchanda, P., \& Chintagunta, P. K. (2010). The effect of signal quality and contiguous word of mouth on customer acquisition for a video-on-demand service, Marketing Science, 29 (4), 690-700.

Narayanan, S., \& Manchanda, P. (2009). Heterogeneous learning and the targeting of marketing communication for new products, Marketing Science, 28 (3), 424441.

Nelson, P. (1970). Information and consumer behavior, Journal of Political Economy, 78 (2) , 311-329.

Nelson, P. (1974). Advertising as information, Journal of Political Economy, 82 (4), 729754. 
Pavlou, P. A., \& Gefen, D. (2004). Building effective online marketplaces with institutionbased trust. Information Systems Research, 15 (1), 37-59.

Purnawirawan, N., De Pelsmacker, P., \& Dens, N. (2012). Balance and sequence in online reviews: How perceived usefulness affects attitudes and intentions, Journal of interactive marketing, 26 (4), 244-255.

Qiu, L., Pang, J., \& Lim, K. H. (2012). Effects of conflicting aggregated rating on eWOM review credibility and diagnosticity: The moderating role of review valence, Decision Support Systems, 54 (1), 631-643.

Ruef, M., Aldrich, H. E., \& Carter, N. M. (2003). The structure of founding teams: Homophily, strong ties, and isolation among US entrepreneurs. American Sociological Review, 68 (2), 195-222.

Schubert, P., \& Ginsburg, M. (2000). Virtual communities of transaction: The role of personalization in electronic commerce, Electronic Markets, 10 (1), 45-55.

Shimp, T. A, \& Bearden, W. O. (1982). Warranty and other extrinsic cue effects on consumers' risk perceptions, Journal of Consumer Research, 9 (1), 38-46.

Sun, M. (2012). How does the variance of product ratings matter?, Management Science, 58 (4), 696-707.

Wallace, W. T., Seigerman, A., \& Holbrook, M. B. (1993). The role of actors and actresses in the success of films: How much is a movie star worth?, Journal of Cultural Economics, 17 (1), 1-27.

Wan, Y., Nakayama, M., \& Sutcliffe, N. (2012). The impact of age and shopping experiences on the classification of search, experience, and credence goods in online shopping, Information Systems and e-Business Management, 10 (1), 135-148.

Weathers, D., Sharma, S., \& Wood, S. L. (2007). Effects of online communication practices on consumer perceptions of performance uncertainty for search and experience goods, Journal of Retailing, 83 (4), 393-401.

Wellman, B., Boase, J., \& Chen, W. (2002). The networked nature of community: Online and offline, It \& Society, 1 (1), 151-165.

Wright, A. A., \& Lynch Jr, J. G. (1995). Communication effects of advertising versus direct experience when both search and experience attributes are present, Journal of Consumer Research, 21 (4), 708-718.

Yang, J., Kim, W., Amblee, N., \& Jeong, J. (2012). The heterogeneous effect of WOM on product sales: why the effect of WOM valence is mixed?, European Journal of Marketing, 46 (11-12), 1523-1538.

Yin, D., Mitra, S., \& Zhang, H. (2016). Research note-When do consumers value positive vs. negative reviews? An empirical investigation of confirmation bias in online word of mouth, Information Systems Research, 27 
(1), 131-144.

Zeithaml, V. A. (1981). How consumer evaluation processes differ between goods and services, in Donnelly, J.A. and George, W.R. (Eds). Marketing of Services, American Marketing Association, Chicago, IL, 186-190.

Zhang, L., Choi, K., \& Lee, J. (2017). The periodic relationship between eWOM volume/ valence and box office revenue, Knowledge Management Research, 18 (2), 65-83.

Zhu, F., \& Zhang, X. (2010). Impact of online consumer reviews on sales: The moderating role of product and consumer characteristics, Journal of Marketing, 74 (2), 133-148. 